\title{
Minimally-Invasive Assessments of the Behavioural and Physiological Effects of Enriched Colony Cages on Laying Hens
}

\author{
N. J. Cook*, A. L. Schaefer ${ }^{\dagger}$, D. R. Korver ${ }^{\ddagger}$, D. B. Haley ${ }^{\S}$, J. J. R. Feddes ${ }^{\ddagger}$, and J. S. Church ${ }^{\#}$ \\ "Alberta Agriculture and Rural Development, Lacombe Research Centre, Alberta, Canada; ${ }^{\dagger}$ Agriculture and Agri-Food \\ Canada, Lacombe Research Centre, Alberta, Canada; ${ }^{\S}$ University of Guelph, Ontario, Canada; ${ }^{*}$ University of Alberta, \\ Edmonton, Alberta, Canada; ${ }^{\#}$ Thompson Rivers University, Kamloops, British Columbia, Canada
}

\begin{abstract}
The well-being of laying hens in cages of 5, 10, 20 and 40-birds/cage, and enrichment with perches, nest boxes and scratch pads, was assessed using behavioral and physiological parameters. Laying hens were Lohmann Brown ( $\mathrm{n}=$ $360)$ and White Leghorns $(n=360)$, housed from 17 to 65 weeks of age. Behavioral parameters were; the percentage of birds per cage roosting on perches, claw length $(n=288)$, and the percentage of eggs laid within nest boxes. Physiological parameters were; the assessment of feather cover from measurements of radiated temperatures by infrared thermography (IRT), bone mineral content of the humerus and femur by quantitative computer tomography (QCT) scans, and adrenocortical function as a marker of chronic stress by measurements of corticosterone concentrations in egg yolk and albumin.

The majority of eggs $(72.7 \%)$ in furnished cages were laid in nest boxes. Nest use was highest in Brown hens $(\mathrm{P}<0.03)$. Perch use was $>80 \%$, but significantly less in the 10-bird cages $(\mathrm{P}<0.0012)$ due to a shorter perch length. Claws were shorter on birds in cages with scratch pads $(\mathrm{P}<0.0001)$. Feather insulation declined from 35 to 60 weeks of age for breast and back areas $(\mathrm{P}<0.0001)$. White birds exhibited superior breast feather insulation compared to Brown birds. Egg albumin corticosterone levels declined between 35 and 60 weeks of age $(\mathrm{P}<0.011)$. There were no indications of an affect of colony size or cage enrichment on measurements of bone mineral content. The findings indicated a preference for the use of nest boxes, perches and scratch pads. Significant losses in feather insulation occur with time. A reduction in egg albumin corticosterone levels over time may be a marker of chronic stress in caged laying hens.
\end{abstract}

Keywords: Laying hens, colony cages, feather cover, infrared thermography, chronic stress, egg corticosterone, bone mineral content, behavior, welfare.

\section{INTRODUCTION}

Concerns regarding the welfare of intensively housed hens have resulted in the legislated phasing out of conventional battery cages in the European Union by 2012 [1]. Thereafter, only 'enriched' cages that include nest boxes, perches, scratching area, and a floor area of $750 \mathrm{~cm}^{2}$ per bird, will be permitted. In contrast, approximately $98 \%$ of laying hens in North America are housed in non-enriched, battery cages with floor areas ranging from $432 \mathrm{~cm}^{2}$ to 554 $\mathrm{cm}^{2}$ per bird, "depending on the size of the hen" [2].

Mandated changes to the housing of laying hens in the European Union have been driven by recognition that the performance of natural behaviors is important for hen welfare [3]. Caged systems, particularly non-enriched cages, cannot provide the same environmental enrichment as 'open' systems such as free-range. However, it does not necessarily follow that open systems are more conducive to the wellbeing of hens since a different set of welfare insults may apply, e.g. predation and increased exposure to pathogens. Laying hens in litter-based and free-range housing systems

*Address correspondence to this author at the Alberta Agriculture and Rural Development, Lacombe Research Centre, 6000 C\&E Trial, Lacombe, Alberta, Canada, T4L 1W1; Tel: (403) 782 8057; Fax: (403) 782 6120;

E-mial:nigel.cook@gov.ab.ca exhibit higher mortality rates associated with increased occurrence of bacterial, parasitic and viral diseases, and higher rates of cannibalism, compared to hens in cages [4]. Nevertheless, within caged systems, the ability to perform natural behaviors such as dust bathing, nesting, scratching, perching and wing flapping, coupled with factors such as stocking density, colony size, social status, and breed, individually and collectively impact on the well-being of laying hens $[5,6]$

Probably the single greatest impact on the well-being of laying hens housed in cages is stocking density; more so than the provision of furnishings [7]. For any given housing density the more birds in the colony the greater the available free space [8]. However, as the size of the colony increases there is growing impact of social order within the group leading to a higher incidence of aggression. Thus, as the size of the colony increases there is a trade-off between increasing free space per hen and the likelihood of experiencing aggression. The present study focused on colony size as the main variable, with housing density held constant across colony sizes.

Another potential source of stress on laying hens in enriched colony cages is competition for the facilities provided. If the facilities are inadequate to meet the needs of all birds, or promotes competition among birds for access to those facilities, then inadequate provision of facilities may constitute a source of stress. In the present study, specific aspects 
of environmental enrichment were selected that could be incorporated within the main effect at different rates. Thus, nest boxes and scratch pads were provided at rates of 1 per 10 or 20 birds, and perch length per bird varied among cage sizes. An unfurnished cage was included in the study to draw comparisons between conventional, battery-style housing and enriched, colony housing. Thus, the primary objectives were to examine the effects of colony size and the provision of enrichment facilities at differing rates on the well-being of laying hens.

The assessment of hen welfare utilized a number of parameters of well-being. An objective was to use minimallyinvasive assessment techniques on live birds to reduce the confounding influence of handling on stress responses. Behavioral assessments included observations of perch use for roosting, the preference for nest boxes to lay eggs, and the measurement of claw length as an indicator of the use of scratch pads. A measure that is often used as a marker of compromised welfare is feather cover [9]. Feather losses or degradation in feather quality may result from excessive preening, incidental contact with cage structures, and feather pecking by cohorts. The latter cause of feather losses is often used as an indirect measure of aggression. Lack of feather cover, irrespective of the underlying causes, is a welfare insult because it affects the thermal comfort of the birds [10]. Feather cover is most often assessed using subjective scales [11], but a more accurate and precise method of assessing feather cover is to measure radiated heat loses by infrared thermography (IRT) [12]. Thus, temperature measurements and profiles from IRT images were constructed and compared among housing conditions.

Osteoporosis in laying hens is common, and is generally regarded as occurring due to loss of calcium from structural bone to support formation of eggshells over the course of the production cycle [13]. Breakage of leg and wing bones frequently occurs at the end the production cycle when hens are removed from their cages $[14,15]$. Mitigation of osteoporosis and preservation of bone volume may lead to a reduction in the incidence of bone breakages, and have been associated with the provision of perches and scratch pads [16-18]. Bone mineralization can be accurately and precisely measured by quantitative computer tomography (QCT) scans. This technique has previously been used to assess mineralization of the bones of laying hens at the end of the production cycle [19] and in response to housing conditions [20]. In the present study, the effect of cage enrichment, i.e. perches and scratch pads, on the mineral content of the humerus and femur was assessed from the measurement of bone densities and areas by QCT scans.

A commonly employed biomarker of endocrine responses to stress is the measurement of blood levels of corticosterone. Guesdon et al., [21] did not find differences in blood levels of corticosterone between birds housed in conventional and enriched colony cages, either before or after stimulation with ACTH. However, this may have been due to the confounding effect of handling the birds to obtain blood samples, or because any differences were masked by the adrenal response to ACTH stimulation. The measurement of egg levels of corticosterone provides a non-invasive method of assessing adrenal activity that avoids the confounding effects of handling. The transfer of circulating ma- ternal corticosterone to egg yolk and albumin, and an increase in egg levels in response to acute stress have been documented [6, 22-24]. Plasma levels of corticosterone, integrated over a period of 8 hours, have been shown to correlated with yolk and albumin levels of corticosterone in eggs collected 1-2 days later [25]. Reductions in egg corticosterone levels over time within caged birds may indicate adaptation to environmental conditions [26]. Thus, egg albumin and yolk concentrations of corticosterone have the potential to assess stress responses to the environment and adaptation of the hypothalamic-pituitary-adrenocortical (HPA) axis to environmental conditions. The measurement of egg corticosterone provided a non-invasive method of assessing longer term changes to adrenocortical output in response to housing conditions.

The study utilized a housing system that could be operated as a conventional battery cage system, or be converted to enriched colony cages of varying sizes. The availability of scratch pads, nest boxes and perches varied among differently sized cages. The effects of colony size or enrichment facilities on hen well-being were evaluated using observations of behavior and by quantitative measures of physiological responses to housing conditions. The applications of QCT for bone mineralization, IRT for feather cover, and egg corticosterone measurements as markers of chronic stress, have not been previously combined in a single study of the well-being of laying hens. Thus, the research objectives of the present study was to assess the welfare benefits, or otherwise, of colony size and environmental enrichments using behavioral observations of the use of the facilities provided, and to assess the impact on measures of chronic stress, feather cover and bone mineral content.

\section{MATERIALS AND METHODS}

\section{Laying Hens and Management}

The study was conducted at the Poultry Research Centre, University of Alberta and in accordance with the Canadian Guide on the Care and Use of Experimental Animals [27]. Birds were Lohmann White $(\mathrm{n}=360)$ and Lohmann Brown $(\mathrm{n}=360)$ laying hens reared at the University of Alberta, Poultry Research Centre and placed into the experimental cages at 17 weeks of age. Birds were provided ad libitum access to water and a standard commercial layer diet. The commercial diet was supplemented with $5 \mathrm{~g}$ of oyster shell per bird once per week after 40 weeks of age, to provide the birds with a calcium source to mitigate the loss of calcium from bone.

\section{Cage Layout}

The cage system was built by Techno Poultry Equipment (Padova, Italy). The cage system was chosen because of the ease of configuring the internal cages into either unfurnished or enriched cages, of varying sizes. The overall dimensions of the cage system were $14.4 \mathrm{~m}$ long $\times 1.2 \mathrm{~m}$ wide (not including egg collection belts and feed troughs) and divided into three tiers. Each tier was subdivided into cages containing 5, 10, 20 or 40 birds per cage. Internal cages were from $45 \mathrm{~cm}$ to $52.5 \mathrm{~cm}$ in height due to a sloping floor to permit eggs to roll out of the cage and onto the collection belt. All internal cages irrespective of colony size provided a floor 
Fig la: Top Tier

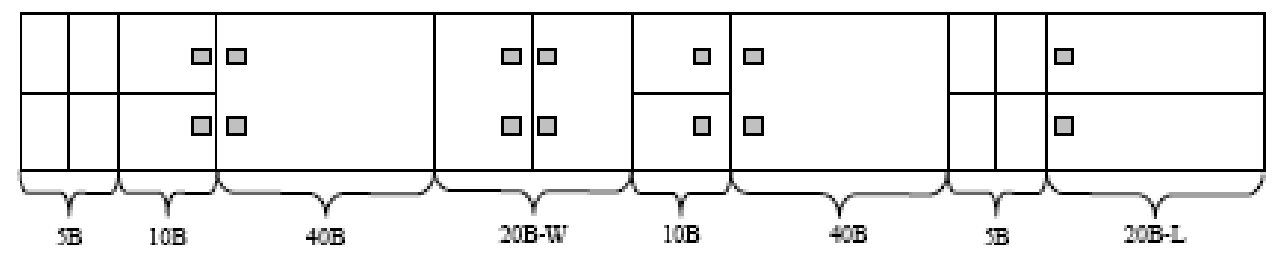

Fig lb: Middle Tier

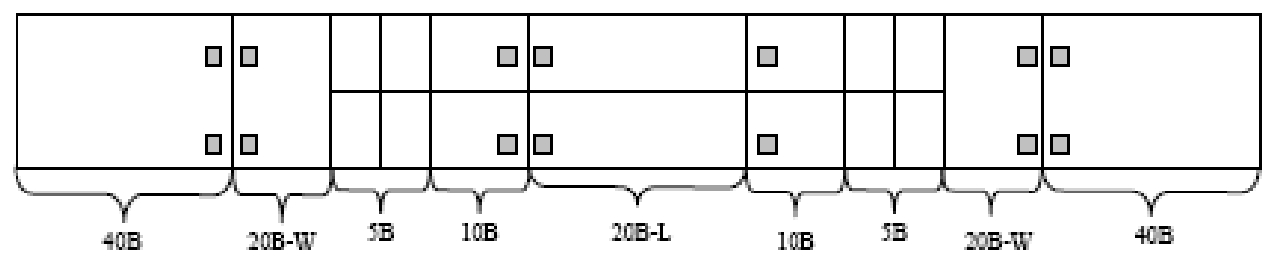

Fig 1c: Boctom Tier

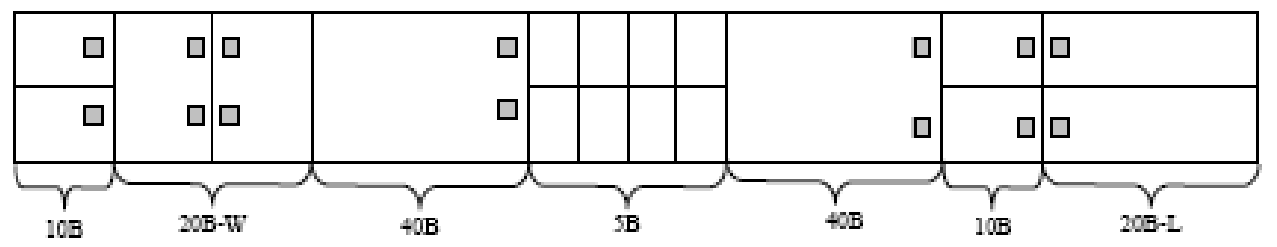

Fig. (1). Arrangements of cages within Tiers and the position of nest boxes within colony cages.

area of $767 \mathrm{~cm}^{2}$ per bird. Fig. (1) shows the internal configuration of colony cages within Tiers, and the positions of nest boxes within furnished cages. Note that Fig. (1) is a diagrammatic representation of the position of cages and not drawn to scale. There were two types of 20-bird (20B) cages that differed with respect to their orientation within the main cage structure. The $20 \mathrm{~B}$ cages that spanned the width of the main cage were designated as $20 \mathrm{~B}-W$ ide $(20 \mathrm{~B}-\mathrm{W})$, and those orientated along the length of the main cage were called 20B-Long (20B-L).

Fig. (2) shows an example of a 40-bird (40B) cage with nest boxes, perches and scratch pads. The 10B and 20B-L cages contained one nest box and scratch pad per cage, and the $20 \mathrm{~B}-\mathrm{W}$ and $40 \mathrm{~B}$ cages contained 2 nest boxes and scratch pads. The nest boxes were constructed from plastic curtains, and covered a floor area of $900 \mathrm{~cm}^{2}$ (Fig. 2). The scratch pads were constructed from steel plate, and covered an area of $756 \mathrm{~cm}^{2}$ (Fig. 2). Colony size and furnishings are summarized in Table 1. Note that colony size and perch length co-varied. Thus, to test the affect of perch length independently from colony size it was necessary to test for differences between the 20B-L and 20B-W cages.

\section{Welfare Assessment Parameters}

\section{Behavioral Observations}

Direct observations of the use of cage furnishings for roosting were made by an observer who recorded the numbers of birds roosting on perches, floor, scratch pads, and in nest boxes. These data were recorded within a two-hour period beginning one hour into the dark phase, from 20:00h to 22:00h. Four sets of observations were recorded within each two-hour period at 57,61 and 62 weeks of age.
The numbers of eggs laid in nest boxes and on scratch pads were estimated by counting the eggs on the collection belt adjacent to these furnishings, on three separate occasions 21-days apart (57, 60 and 63 weeks of age). Eggs located on the collection belt between these points were assumed to have been laid on the cage floor. The numbers of eggs laid at each location were expressed as the percentage of the total numbers of eggs laid per cage, and a comparison of these percentages indicated the bird's preferred location for oviposition.

At the end of the study, birds were euthanized by cervical dislocation and the length of the nail on the middle toe was measured along the coronal (upper) surface of the claw from toe skin to the tip of the claw to assess the effect of scratch pads as claw shortening devices.

\section{Feather Cover by Infrared Thermography (IRT)}

Infrared images of the breast and back views of 144 birds were recorded using a SC640 and a P60 ThermoCAM infrared cameras (Flir Vision Systems, ON) at 35 and 60 weeks of age, respectively. Thermographic images were analyzed for temperature data using ThermaCAM Researcher Pro (v2.7) software. To correct for the effect of 'camera', a Black Body infrared calibrator (Omega, QC) was used to normalize the data from each IRT camera. The relationships between the Black Body calibrator and each of the IRT cameras were described by linear equations. These equations were applied to the thermal data of the bird images so that the temperature data obtained at 35 weeks and 60 weeks were normalized to the Black Body calibrator. Temperature distribution profiles of the breast and back IRT images were constructed by plotting the percentage area of the images within temperature intervals of $1{ }^{\circ} \mathrm{C}$ [12]. Temperature data from IRT images 


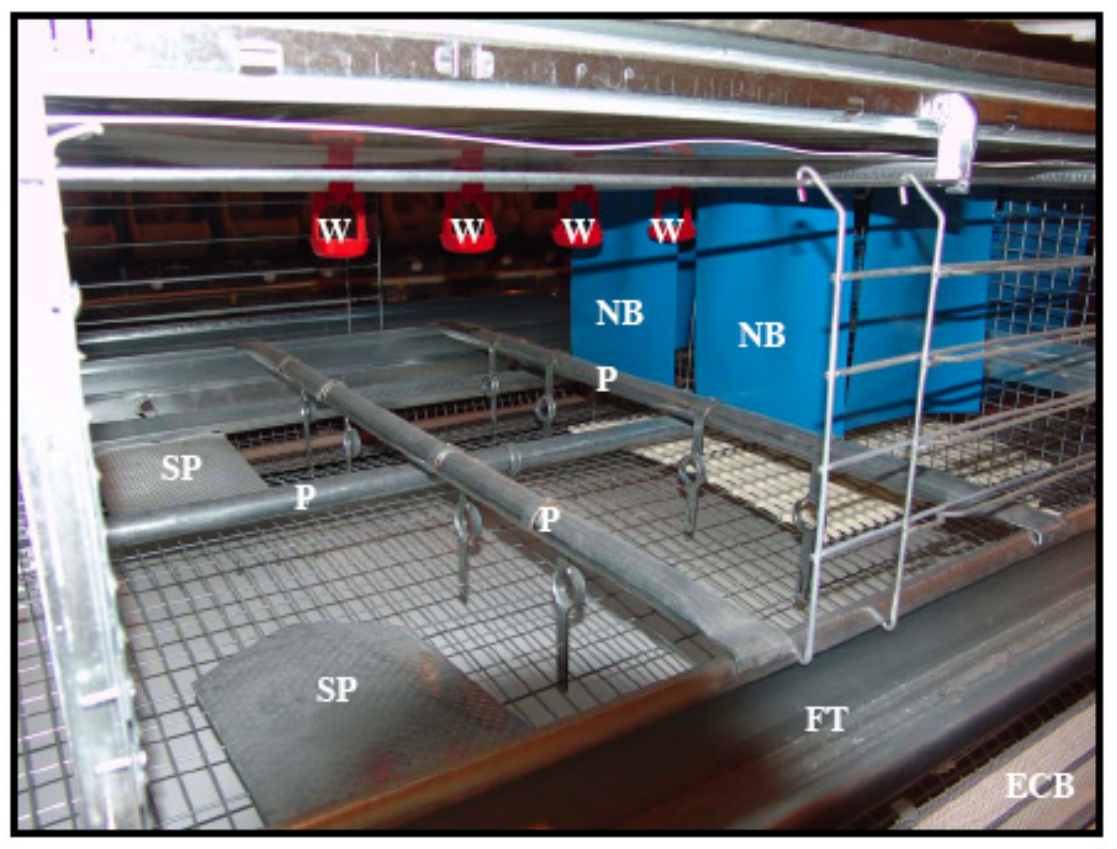

$$
\begin{aligned}
& \text { NB = Nest box } \\
& \text { SP = Scratch pad } \\
& \text { P = Perches } \\
& \text { FT = Feed trough } \\
& \text { ECB = Egg collection belt } \\
& \text { W = Water }
\end{aligned}
$$

Fig. (2). 40-bird colony cage showing arrangement of nest boxes, perches and scratch pads.

Table 1. Cage Types, Colony Size and Furnishings per Cage

\begin{tabular}{|c|c|c|c|c|c|}
\hline Cage Type & Cages (N) & Colony Size (N) & $\begin{array}{c}\text { Perch Length } \\
\text { (cm Per Bird) }\end{array}$ & $\begin{array}{c}\text { Scratch Pads } \\
\text { (Birds Per Pad) }\end{array}$ & Noxes \\
(Birds Per Nest)
\end{tabular}

included the minimum, maximum, range and mean image temperatures.

\section{Bone Mineral Content by Quantitative Computer Tomo- graphy}

At 65 weeks of age 12 euthanized birds from each cage type ( 6 of each Strain; total $n=60$ ) were randomly selected for bone density and cross-sectional area measurements by QCT scans as previously described [19]. The right femur was removed by dislocation at the hip and knee joints, and the right humerus was removed at the shoulder. The whole bone (femur and humerus) was initially scanned at low resolution to define the proximal and distal ends. Based on those markers, a high-resolution scan was conducted at the midpoint of the bone. The resultant scan provided a cross- sectional measurement of a $1 \mathrm{~mm}$ length of bone. Mineral density and cross-sectional areas of cortical bone, bone in the trabecular space that included trabecular and medullary bone types, and the total bone were measured. Bone strength is a function of both size and density of the bone and thus the density measurements were adjusted by multiplying by the cross sectional areas. The resultant product was termed the 'bone mineral content' (BMC) and gives the area adjusted density $\left(\mathrm{mg} / \mathrm{mm}^{3}\right)$ over a $1 \mathrm{~mm}$ length at the mid-point of the bone.

\section{Egg Yolk and Albumin Corticosterone}

Eggs $(n=144)$ were collected at 35 weeks and 60 weeks of age ( $n=72$ eggs per sample time) with eggs from Brown and White birds equally represented. Sub-samples of 12 eggs 
were collected from the 5B and $10 \mathrm{~B}$ cages and 24 eggs from the $20 \mathrm{~B}$ and $40 \mathrm{~B}$ cages. The eggs were frozen at $-40{ }^{\circ} \mathrm{C}$ until sample processing and measurement of corticosterone concentration by enzyme immunoassay [25]. The frozen albumin and yolk were separated and freeze dried. The whole freeze dried albumin and yolk were homogenated and a subsample of $100 \mathrm{mg}$ taken for analysis. Corticosterone was extracted in multiple steps utilizing a mixture of organic solvents (petroleum ether/diethyl ether, ethanol and hexane). The final extract was dried under nitrogen and reconstituted in assay buffer prior to measurement of corticosterone concentrations using the corticosterone Correlate-EIA kit (Assay Design, MA). Concentrations of corticosterone were expressed as picograms per milligram ( $\mathrm{pg} / \mathrm{mg}$ ) of freeze dried samples of whole yolk and albumin.

\section{Statistical Analyses}

Measurement parameters were statistically analyzed by mixed model analysis of variance using JMP (v6) (SAS Institute, 2005). Fixed effects were Colony Size (birds per cage), Amenities (10 or 20 birds per nest box and scratch pad), Cage Type (perch length), Tier (top, middle and bottom) and Strain (brown and white). As previously noted there was a large degree of co-variation between Cage Type (perch length) and Colony Size, and consequently any statistically significant effects of Colony Size on any of the parameters of well-being were tested for the effect of perch length by direct comparisons between 20B-W and 20B-L cages. Also, note that bird weight was not recorded and therefore BMC could not be expressed as a function of weight. Since there could have been weight differences between Strains the effect of Strain was not included in mixed model analysis of BMC.

Measurements of claw length and bone mineral content were recorded post-mortem at the end of the study. Fixed effects for claw length were Strain, Tier, Cage Type, Amenities, and their interactions.

Temperature measurements by IRT and egg corticosterone measurements were made on more than one sample day but not on the same birds. Consequently, the fixed effect of 'Sample' was included in mixed model analyses, and all other fixed effects and their interactions were tested within Sample.

Observations of roosting and nesting behavior were made on 4 and 3 sampling occasions, respectively. However, sample time was not a significant effect for observations of roosting and nesting behaviour and consequently data from individual sample times were combined and expressed as the mean of sample times.

The experimental unit was the cage and Cage ID was designated as a random effect in all statistical analyses.

\section{RESULTS}

The mortality rate over the study was $2.4 \%($ Brown $=1.9$ $\%$ and White $=2.8 \%$ ). There were no differences in mortality rates among Strains, Cages or Tiers.

\section{Roosting Behaviour Observations}

The mean percentages of birds over all sampling times and Cage Types using the perches for roosting was $86.3 \%$, with $6.6 \%$ using the scratch pads, $1.6 \%$ roosting in the nest boxes, $3.8 \%$ roosting on the floor and $1.7 \%$ not roosting. Fewer birds in the $10 \mathrm{~B}$ cages utilized the perches for roosting compared to all of the other enriched cages $(\mathrm{P}=0.0012)$.

\section{Nest Boxes for Oviposition}

There was no affect of Strain $(\mathrm{P}=0.36)$ or Tier $(\mathrm{P}=$ 0.29 ) on the numbers of eggs produced in furnished cages. The majority of eggs $(72.7 \%)$ were laid in nest boxes, with $15.5 \%$ laid on the scratch pads and $11.8 \%$ on the floor. Brown birds laid more eggs $(\mathrm{P}<0.0001)$ in nest boxes $(85.9 \%)$ than White birds $(56 \%)$. The percentage of eggs laid in nest boxes was higher $(\mathrm{P}=0.0033)$ in the Top Tier (84.4\%) compared to the Bottom Tier $(61.9 \%)$, and higher $(\mathrm{P}$ $=0.016)$ compared to the Middle Tier (66.6\%). There were no differences $(P=0.53)$ in the percentages of eggs laid in nest boxes between the Bottom and Middle Tiers.

\section{Claw Length}

Strain $(\mathrm{P}<0.0001)$ and Amenities $(\mathrm{P}=0.0004)$ were significant fixed effects. White birds exhibited longer claw length than Brown birds (2.2 $\mathrm{mm}$ vs. $1.9 \mathrm{~mm}$, respectively). Birds in $5 \mathrm{~B}$ cages without scratch pads had significantly longer claws than birds in cages provided with a scratch pad $(\mathrm{P}<0.0001)$. However, there were no differences in mean claw length between birds provided with a scratch pad per 10 birds compared with 1 pad per 20 birds.

\section{Bone Mineral Content by Quantitative Computer Tomo- graphy}

The BMC was not affected by fixed effects that included Colony Size, Amenities, Cage Type or Tier.

\section{Assessment of Feather Cover by Infrared Thermogra- phy}

Temperature data obtained from thermographic images were the minimum, maximum, range and average image temperatures. The minimum image temperature exhibited very little variation because nearly all birds possessed some feather cover. As a consequence the range in image temperature closely paralleled the maximum image temperature because the bottom of the range, i.e. the minimum image temperature, was essentially the same for all images. Thus, the image temperature data that best represented feather cover were the average and maximum image temperatures, and statistical analyses were limited to these parameters. The means (SD) for the average and maximum breast and back image temperatures for Brown and White strains at 35 and 60 weeks are given in Table 2.

All temperature parameters were significantly higher in images recorded at 60 weeks compared to 35 weeks $(\mathrm{P}<$ $0.0001)$. The maximum breast image temperatures at 35 weeks were higher in the Brown compared to the White birds. At 60 weeks both the image average and maximum temperatures were higher in the Brown birds.

The back image temperatures were significantly higher in the White birds at 35 weeks but by 65 weeks the Brown birds exhibited numerically higher back temperatures, although the differences were not statistically significant. There were no consistent differences in temperature meas- 
Table 2. Mean (SD) of Average and Maximum Image Temperatures of the Breast and Back of Brown and White Birds at 35 and 60 Weeks

\begin{tabular}{|c|c|c|c|c|c|}
\hline \multirow[b]{2}{*}{ Location } & \multirow[b]{2}{*}{ Strain } & \multicolumn{2}{|c|}{ Week 35} & \multicolumn{2}{|c|}{ Week 60} \\
\hline & & Average & Maximum & Average & Maximum \\
\hline \multirow{2}{*}{ Breast } & White & $26.4(0.61)$ & $33.8(1.92$ & $29.6(1.28)$ & $39.0(0.81)$ \\
\hline & $\mathrm{P}=$ & 0.07 & 0.0001 & 0.0014 & 0.0001 \\
\hline \multirow{2}{*}{ Back } & White & $23.6(0.55)$ & $28.9(1.37)$ & $26.6(1.02)$ & $36.2(3.09)$ \\
\hline & $\mathrm{P}=$ & 0.0005 & 0.021 & 0.105 & 0.16 \\
\hline
\end{tabular}

urements of either the back or breast areas among other fixed effects.

Temperature distribution profiles were constructed to provide an illustration of temperature differences among anatomical locations and over time. Temperature profiles were constructed by plotting the area of the image, represented as the percentage of pixels, within temperature intervals of $1{ }^{\circ} \mathrm{C}$ for breast and back images at 35 weeks and 60 weeks (Fig. 3). To make quantitative comparisons among temperature profiles it was necessary to choose a referent temperature. Although the choice of referent was largely arbitrary, using the lowest temperature threshold that contained $100 \%$ of an image profile provided a comparison to the 'best' feather cover. Consequently, $100 \%$ of the back image area in 35 week images was below a threshold of 30 ${ }^{\circ} \mathrm{C}$, and this temperature was subsequently used as a referent for comparative purposes. The profiles in Fig. (3) illustrated the substantial loss of insulation over time for breast and back locations. Between 35 and 60 weeks, the area of the back $>30{ }^{\circ} \mathrm{C}$ increased from zero to $6.1 \%$ of the image. Whereas, the area of the breast images $>30^{\circ} \mathrm{C}$ increased from $3 \%$ at 35 weeks to $25.7 \%$ at 60 weeks. The back temperature profiles were substantially the same shape for images at 35 week and 60 weeks, except that the 60 week profile was shifted to a higher temperature scale. The breast image profile was also shifted overall to a higher temperature range but with a long 'tail' in the distribution to the high end of the scale. Note there was an increase in the area of the image $>35^{\circ} \mathrm{C}$ that represented bare skin. The back area at 60 weeks $>35{ }^{\circ} \mathrm{C}$ was $4 \%$, whereas the breast area $>35{ }^{\circ} \mathrm{C}$ was 11.3 $\%$. Thus, in terms of the areas of exposed skin, the breast area exhibited much more severe feather losses than the back area.

\section{Yolk and Albumin Corticosteroid Measurements}

There was no difference in yolk corticosterone levels between eggs collected at 35 and 60 weeks, and none of the fixed effects were of statistical significance for yolk corticosterone concentrations.

Albumin corticosterone levels were significantly lower $(\mathrm{P}=0.011)$ in eggs collected at 60 weeks $(52.6 \pm 73.4 \mathrm{pg} / \mathrm{mg})$ compared to eggs collected at 35 weeks $(94.7 \pm 116.1$ $\mathrm{pg} / \mathrm{mg}$ ). Due to the large standard deviations these data were reanalyzed after the albumin corticosterone concentrations were $\log _{10}$ transformed. After $\log _{10}$ transformation the statistical difference in albumin corticosterone levels between eggs collected at 35 and 60 weeks remained significant $(\mathrm{P}=$ $0.0002)$. There were no other statistically significant effects on albumin corticosterone concentrations.

\section{DISCUSSION}

The results of the present study are in agreement with previous studies, reviewed by Appleby and Hughes [3], that have shown preferences of laying hens to use nest boxes, perches and to scratch in sand boxes. Observations of behaviour clearly demonstrated that hens preferred to roost on perches, and if space on the perch was not available then nest boxes and even scratch pads were preferable to roosting on the wire floors. The provision of sufficient perch length for all birds to roost at night is an obvious welfare advantage over unfurnished cages. The significantly lower perch use in the $10 \mathrm{~B}$ cages suggested that $15 \mathrm{~cm}$ of perch length per bird was insufficient for all birds to roost.

The Brown strain in particular exhibited a strong preference for the use of a nest box for egg laying. Use of the nest boxes was higher in the Top compared to the Middle and Bottom Tiers, which was probably due to lighting in the barn. The cages of the Top Tier were much closer to the lights on the ceiling of the barn. Birds can exhibit a preference for oviposition under dim lighting conditions and therefore were more likely to seek these conditions in the nest boxes of the Top Tier where lighting was most intense. In some commercial barns with furnished colony cages, fluorescent bulbs are hung vertically from the ceiling rather than mounted horizontally. The bulbs are hung between cages at a point furthest away from the nest boxes. This produces a more even distribution of light across Tiers, reduces harsh lighting conditions in the Tiers nearest the ceiling, and ensures that the nest boxes are furthest from the lighting source. Under these conditions more hens are encouraged to use the nest boxes and consequently the incidence of cracked or broken eggs is reduced. More eggs were laid on the scratch pads than on the floor of the cage, suggesting that the surface on which hens lay their eggs is important to the birds. Thus, avoiding mesh-type flooring in the nest boxes may further promote their use.

The use of scratch pads was inferred by measurements of claw length, which were shorter in cages containing a scratch 


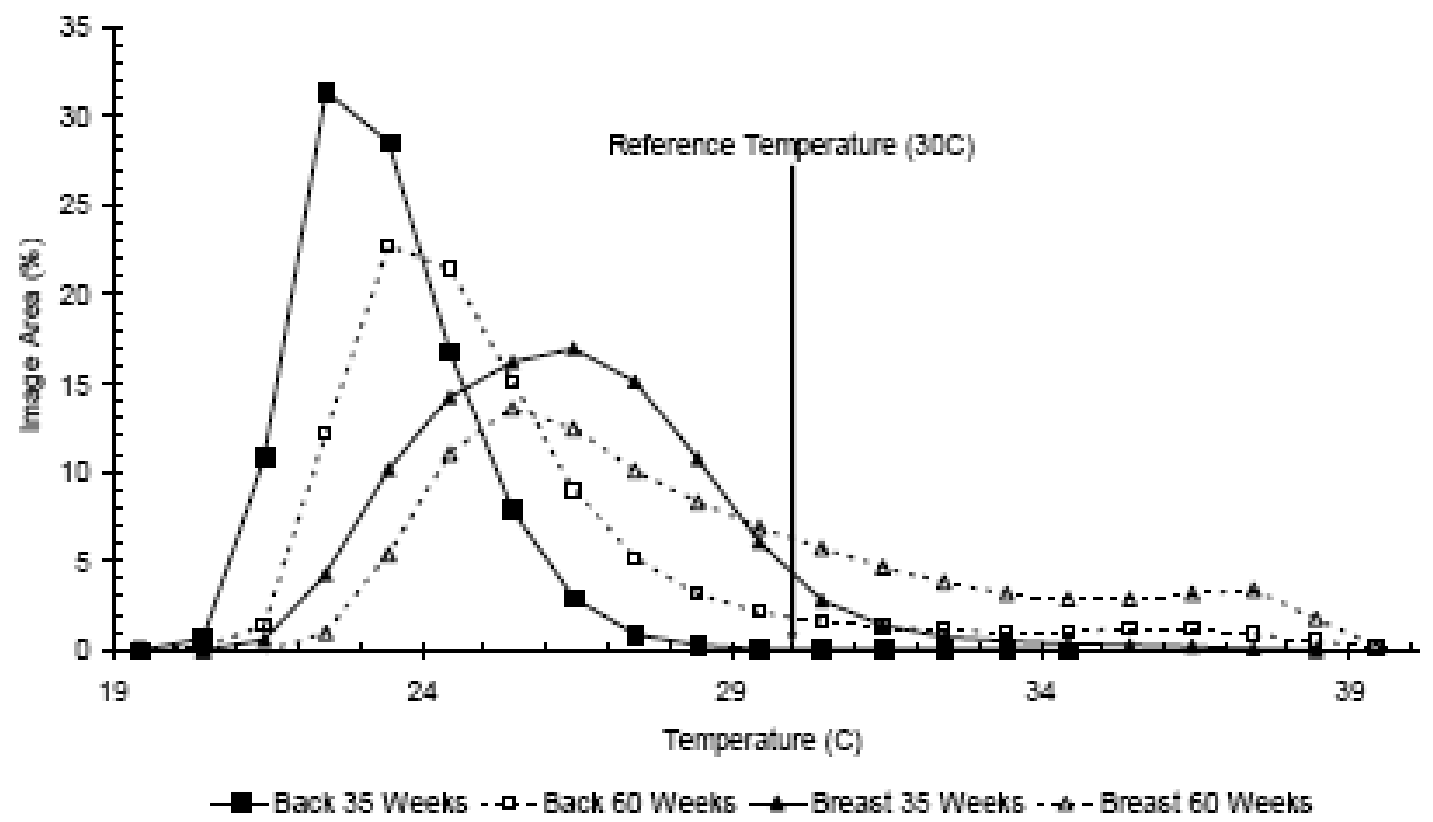

Fig. (3). Temperature distribution profiles for breast and back images taken at 35 and 60 weeks. A referent temperature of $30^{\circ} \mathrm{C}$ was chosen for comparative purposes.

pad. However, there were no differences in claw lengths among birds provided with a pad per 10 or 20 birds. This lack of difference suggested that claw wear was not an incidental event but the result of an activity performed by the birds. The position and shape of the scratch pads is probably important. Scratching is associated with feeding behavior and thus scratch pads should be positioned in front of the feed trough, as in the present configuration. However, a scratch pad strip that runs the length of the cage would likely be more effective than the plate configuration used in the present study. The claw-shortening effect may have been partly due to birds using the scratch pads for roosting.

The observations of roosting behavior, sites for egg laying, and measurements of claw length strongly indicated that the provision of perches, nest boxes and scratch pads permitted the expression of natural behaviors that would not be possible in conventional battery cages, and were entirely consistent with numerous other studies concerned with the well-being of laying hens.

Previous studies have suggested that perch use can maintain the strength of the leg bones of laying hens $[16,18]$ and that this is a function of maintaining bone volume [17] and density [20]. Nevertheless, in a comparison among laying hens housed in unfurnished and furnished cages there were no significant affects of the housing conditions on the weight, breaking strength, elastic strain or stiffness of the humerus [21]. In the present study, there was no evidence to suggest that perches induced a physiological effect on bone mineralization. The discrepancies among studies may be a function of the area provided per bird. The beneficial affect of perches on bone strength is generally ascribed to the dynamic movement of birds on an off perches and, to a lesser extent, the static forces involved in gripping the perch. In the present study, birds were provided with a relatively large area $\left(767 \mathrm{~cm}^{2}\right.$ per bird), which permitted much greater movement than would normally be the case in conventional cages. The increased dynamic forces on the bones associated with greater movement was probably the critical factor mitigating bone mineral losses rather than the provision of perches per se.

Measurements of the insulating properties of feather cover by IRT were a direct measure of bird welfare. Feather loss has a major impact on insulation and thermal comfort, to the extent that poorly feathered birds exhibit a marked increase in feed consumption to compensate for heat losses [10]. Measurement of radiated heat by IRT was able to precisely quantify the loss of insulation over time and the differences among Strains. Irrespective of anatomical location (breast and back) there was significant loss of insulation between 35 weeks and 60 weeks of age. Despite most birds retaining good feather cover over the study period the differences measured between 35 and 60 weeks of age amounted to radiated temperature losses of approximately $4^{\circ} \mathrm{C}$. Strain was a statistically significant affect on radiated temperature measurements. Brown birds exhibited poorer insulation properties of the breast area compared to White birds at both sampling times. Conversely, the backs of Brown birds exhibited superior insulation properties compared to White birds at 35 weeks of age, but the differences disappeared by 60 weeks of age, indicating that the Brown birds lost more insulation on the back area over time than the White strain. Despite the statistical differences in radiated temperature measurements between strains it should be noted that the numerical differences were slight, usually $<1{ }^{\circ} \mathrm{C}$. There was no consistent evidence that colony size or the provision of furnishings had any significant affect on temperature parameters.

The shapes of the temperature distribution profiles provided a graphical representation of the types of insulation losses. The distribution profiles of the breast area revealed a significant increase in the area of the image associated with the temperature of bare skin, i.e. a loss of feather quantity. 
Whereas, the back temperature profile did not exhibit such a marked increase in bare skin but rather a shift in the entire profile to the higher temperature range, indicating a loss in feather quality rather than quantity. Infrared thermography provided a quantifiably accurate measure of heat losses that was capable of differentiating between loss of feather quantity and degradation to feather quality. As such, IRT has potential as an animal-based, outcome measure of the wellbeing of laying hens.

Yolk and albumin levels of corticosterone reflect measurements of corticosterone over the periods of time that yolk and albumin are deposited in the egg, i.e. approximately 10 days and 6 hours, respectively. Consequently, egg corticosterone measurements were an attempt to assess the relative degree of chronic, or long-term, stress among birds housed in the different cage environments. Albumin corticosterone concentrations were lower in eggs collected at 60 weeks compared to 35 weeks of age. This observation is consistent with the results of comparative studies between caged and free-range birds. Albumin corticosterone levels of caged birds, but not free-range birds, were observed to decrease between 22 weeks and 45 weeks of age [26]. Also, albumin corticosterone levels were lower in the eggs of caged compared to free-range birds [28]. Singh et al., [26] suggested that the lower albumin levels observed over time in caged birds might be a reflection of habituation to the cage environment. Bulmer and Gil [28] suggested that chronic stress may manifest itself as a reduction in egg corticosterone levels. In either case, the reported reduction in egg albumin corticosterone levels is probably not a function of age since the effect would have been noted in all housing conditions.

There was no evidence of a similar reduction in yolk corticosterone levels over time. The discrepancy in the observed responses of albumin and yolk levels may be a function of the relative sensitivity of the two measures to changes to the daily output of corticosterone. Albumin is deposited over periods of 5 to 6 hours whereas yolk is deposited over 11 to 12 days. As a consequence, albumin may be the more sensitive measure to changes in daily adrenocortical output.

In summary, the provision of perches, nest boxes and scratch pads for laying hens permitted the expression of a wider repertoire of natural behaviors, and as such should be regarded as improving well-being. There was little evidence that such amenities had any significant impact on bone mineralization, but the provision of more space allowing greater freedom of movement may have mitigated bone mineral losses. Feather quantity and quality can be accurately measured by IRT, which provides a quantifiable, animal-outcome based measure of bird well-being. The evidence of this and other studies suggests that a reduction in egg corticosterone levels over time may be a marker of chronic stress in caged birds.

\section{ACKNOWLEDGEMENTS}

The authors would like to express their sincere thanks for the technical support provided by Denise Froehlich of Alberta Agriculture, Pierre Lepage, Sigrid Marchand, Lavern Holt-Klimec, Jeff Colyn, and Dwight Baird of Agriculture Canada, and Lyle Bouvier and staff at the Poultry Research Centre, University of Alberta.
Financial support was provided by a grant from the Alberta Livestock Industry Development Fund (ALIDF), with contributions from Alberta Egg Producers and Alberta Farm Animal Care (AFAC).

\section{REFERENCES}

[1] Commission of the European Communities (CEC). Council Directive 1999/74/EC Laying down minimum standards for the protection of laying hens. Official J Eur Commun R L 1999; 203: 53-57.

[2] United Egg Producers [www.unitedegg.org]. Animal husbandry guidelines for U.S. egg laying flocks. 2010 ed. Available from: http://www.unitedegg.org/information/pdf/UEP $2010 \quad$ Animal_Welfare_Guidelines.pdf

[3] Appleby MC, Hughes BO. Welfare of laying hens in cages and alternative systems: Environmental, physical and behavioural aspects. World Poult Sci J 1991; 47: 109-28.

[4] Fossum O, Jansson DS, Etterline PE, Vagsholm I. Causes of mortality in laying hens in different housing systems in 2001 to 2004 Acta Vet Scand 2009; 51(3), doi: 10.1186/1751-0147-51-3. Available from: http://www.actavetscand.com/content/51/1/3

[5] Craig JV, Swanson JC. Welfare perspectives on hens kept for egg production. Poult Sci 1994; 73: 921-38.

[6] Downing JA, Bryden WL. A non-invasive test of stress in laying hens. A report for the Rural Industries Research and Development Corporation, RIRDC Publication No 01/143. RIRDC Project No. US-71A, February 2002. Available from: http://www.smallstock.info/reference/RIRDC/01-143.pdf

[7] Shimmura T, Eguchi Y, Uetake K, Tanaka T. Behavior, performance and physical condition of laying hens in conventional and small furnished cages. Anim Sci J 2007; 78: 323-9.

[8] Appleby MC. What causes crowding? Effects of space, facilities and group size on behaviour, with particular reference to furnished cages for hens. Anim Welfare 2004; 13: 313-20.

[9] Rodenburg TB, van Hierden YM, Buitenhuis AJ, et al. Feather pecking in laying hens: new insights and directions for research? Appl Anim Behav Sci 2004; 86(3-4): 291-8.

[10] Tauson R, Svensson SA. Influence of plumage condition on the hen's feed requirement. Swed J Agric Res 1980; 10: 35-9.

[11] Tauson R, Ambrosen T, Elwinger K. Evaluation of procedures for scoring the integument of laying hens - Independent scoring of plumage condition. Acta Agric Scand 1984; 34: 400-8.

[12] Cook NJ, Smykot AB, Holm DE, Fasenko G, Church J. Assessing feather cover of laying hens by infrared thermography. J Appl Poult Sci 2006; 15:274-9.

[13] Whitehead CC, Fleming RH. Osteoporosis in cage layers. Poult Sci 2000; 79:1033-41.

[14] Budgell KL, Silversides FG. Bone breakage in three strains of endof-lay hens. Can J Anim Sci 2004; 84: 745-7.

[15] Gregory NG, Wilkins LJ. Broken bones in domestic fowl: Handling and processing damage in end-of-lay battery hens. Brit Poult Sci 1989; 30: 555-62.

[16] Hughes BO, Appleby MC. Increase in bone strength of spent laying hens housed in modified cages with perches. Vet Rec 1989; 124: 483-4.

[17] Hughes BO, Wilson S, Appleby MC, Smith SF. Comparison of bone volume and strength as measures of skeletal integrity in caged laying hens with access to perches. Res Vet Sci 1993; 54: 202-6.

[18] Layendecker M, Hamman H, Hartung J, et al. Keeping laying hens in furnished cages and an aviary housing system enhances their bone stability. Brit Poult Sci 2005; 46: 536-44.

[19] Riczu CM, Saunders-Blades JL, Yngvesson AK, Robinson FE, Korver DR. End-of-cycle bone quality in white- and brown-egg laying hens. Poult Sci 2004; 83(3): 375-83.

[20] Jendral MJ, Korver DR, Church JS, Feddes JJR. Bone mineral density and breaking strength of white leghorns housed in conventional, modified and commercially available colony battery cages. Poult Sci 2008; 87: 828-37.

[21] Guesdon V, Leterrier C, Constantin P, Guemene D, Couty M, Faure JM. Humeral quality and adrenal responsiveness of laying hens reared in standard and furnished cages. Anim Res 2004; 53: 235-43.

[22] Hayward LS, Wingfield JC. Maternal corticosterone is transferred to avian yolk and may alter offspring growth and adult phenotype. Gen Comp Endoc 2004; 135(3): 365-71. 
[23] Rettenbacher S, Mostl E, Hackl R, Palme R. Corticosterone in chicken eggs. Ann New York Acad Sci 2005; 1046: 193-203.

[24] Saino N, Romano M, Ferrari RP, Martinelli R, Moller AP. Stressed mothers lay eggs with high corticosterone levels which produce low-quality offspring. J Exp Zoo 2005; 303A:998-1006.

[25] Cook NJ, Renema R, Wilkinson C, Schaefer AL. Comparisons among serum, egg albumin and yolk levels of corticosterone as biomarkers of basal and stimulated adrenocortical activity of laying hens. Brit Poult Sci 2009; 50(5): 620-33.

[26] Singh R, Cook NJ, Cheng KM, Silversides FG. Invasive and noninvasive measurment of stress in laying hens kept in conventional cages and in floor pens. Poult Sci 2009; 88: 1346-51.
[27] Canadian Council on Animal Care [www.ccac.ca]. Guide to the care and use of farm animals in research, teaching and testing. ISBN: 978-0-919087-50-7 Canadian Council on Animal Care, Ottawa, ON. Canada, Available from: http://www.ccac.ca/Documents/Standards/Guidelines/Farm_Animals.pdf

.[28] Bulmer E, Gil D. Chronic stress in battery hens: Measuring corticosterone in laying hen eggs. Intl J Poult Sci 2008; 7(9): 880-3.

(C) Cook et al.; Licensee Bentham Open.

This is an open access article licensed under the terms of the Creative Commons Attribution Non-Commercial License (http://creativecommons.org/licenses/by-nc/3.0/) which permits unrestricted, non-commercial use, distribution and reproduction in any medium, provided the work is properly cited. 